\title{
Recurrence rate of basal cell carcinoma with positive histopathological margins and related risk factors*
}

\author{
Fernanda Lara ${ }^{1}$ \\ Luiz Eduardo Fabricio de Melo Garbers²
}

Jesus Rodriguez Santamaría ${ }^{1}$

DOI: http:/ / dx.doi.org/10.1590/abd1806-4841.20174867

\begin{abstract}
BACKGROUND:The best way to approach surgically removed basal cell carcinoma with positive histopathological margins is a controversial issue. Some authors believe that the more appropriate treatment is an immediate reoperation while others prefer a periodic follow up. The rates of recurrence are variable in literature, between $10 \%$ and $67 \%$.

ОвјестіVE: To define the recurrence rate of basal cell carcinoma with positive margins after surgery. Secondarily, identify morphological aspects that can suggest a more frequent tumoral recurrence.

METHODS: This was a retrospective and observational study made by analysis of medical records of 487 patients between January 2003 and December 2009 in Hospital de Clínicas da Universidade Federal do Paraná (HC-UFPR). From 402 basal cell carcinomas surgically treated, 41 fulfilled inclusion criteria and were evaluated for five years or more. Recurrence rate of these tumors was analyzed in all patients and clinical characteristics such as sex, age, tumor size, tumor site, ulceration, and histological type were evaluated in order to find if they were related to more common tumoral recurrence.

RESUlTs: The rate of positive margins after surgery was $12.18 \%$. There were five cases of tumoral recurrence in the observation group and three cases in the re-excision group. Tumor size, site, histological type, ulceration and type of positive margin did not differ statistically between groups. It was not possible to consider if these factors were important in recurrence rates.

STUDY LIMITATIONS: Ideally, a prospective study with a larger sample would be more accurate.

CONCLUSION: The treatment of choice in basal cell carcinoma with positive margins must be individualized to reduce recurrence rates.
\end{abstract}

Keywords: Carcinoma, basal cell; Neoplasm Recurrence, Local ; Reoperation

\section{INTRODUCTION}

Basal cell carcinoma (BCC) is a common cutaneous malignant neoplasm, accounting for $75 \%$ of primary skin tumors of epithelial origin. ${ }^{1-7}$ In the last three decades, there has been an increase in the incidence rates of this tumor from $20 \%$ to $80 \%$ in the United States, an increase that is also perceived worldwide. ${ }^{1}$

The tumor predominantly affects men (2:1 ratio) aged over 40 years, with a mean age of 68 years at diagnosis. ${ }^{1,2,4,7}$ The most common site for appearance of basal cell carcinoma is the head and neck region, preferably in the upper two thirds. ${ }^{1,2,4}$

It is characterized by slow growth and it rarely metastasizes due to its low angiogenic potential. However, due to its local malignancy, it can invade and destroy adjacent tissues., ${ }^{2,6,7,8}$ In rare cases, the neoplasia has a destructive behavior with high rates of relapses and metastases to regional lymph nodes, lungs, bones and skin. ${ }^{1,9}$

Traditional surgical excision has been shown to be effective in the treatment of most basal cell carcinomas, being one of the most frequently used therapeutic modalities. ${ }^{1,3,4,5,10,11}$ The recommended surgical margin is four millimeters, and adequate tumor removal has been demonstrated in $98 \%$ of cases of non-sclerodermiform BCCs, with less than two centimeters in diameter. ${ }^{1,3,10}$ However, in places such as the face, functional and cosmetic issues often do not allow surgical excision with such margin. ${ }^{10}$

Despite adequate excision of the tumor lesions, histological margins involved occur at a variable frequency, between 5.5 and $12.5 \%$ in the international literature. ${ }^{3,7,9,12,13}$ The management of basal cell carcinomas with positive margins remains controversial, with an important dilemma: to surgically enlarge the lesion immediately or to opt for the observation and follow-up of these patients reserving the treatment in the event of subsequent clinical recurrence of the neoplasia. ${ }^{3,4,11,12,14}$ The literature is quite variable in relation to the recurrence rates of these tumors, reporting rates between $10 \%$ and $67 \%{ }^{3,5,6,9,11,12}$ Recurrences between $5 \%$ and $14 \%$ are evident when tumors are completely excised. 3,5

Received on 21.06.2015

Approved by the Advisory Board and accepted for publication on 05.03.2016

* Study conducted at Departament of Clinical Medicine - Universidade Federal do Paraná, Curitiba (PR), Brazil.

Financial Support: None.

Conflict of Interest: None.

Dermatology Departament - Universidade Federal do Paraná (UFPR) - Curitiba (PR), Brazil.

Faculdade Evangélica do Paraná (FEPAR) - Curitiba (PR), Brazil.

(C2017 by Anais Brasileiros de Dermatologia 
In this context, the main objective of this study was to determine the recurrence rates of basal cell carcinoma in patients with microscopic evidence of residual tumor at the margins of surgical resection, evaluated by the Pathology Service of the Hospital de Clínicas of the Federal University of Paraná (HC -UFPR).

Secondly, the study aimed to identify morphological characteristics that could predispose to a greater relapse of these tumors, such as lesion size, tumor site, histological type, presence of ulceration, type of margin compromised and characteristics of the patient, such as age and sex.

Many authors believe that the best approach for a basal cell carcinoma with positive margins in the histopathological examination is immediate reintervention, while others prefer to adopt a more conservative atitude. ${ }^{3,4,11,12,14}$

A more aggressive treatment is not justified in elderly patients, whose clinical conditions are not satisfactory, especially in lesions with a lower risk of relapse. On the other hand, it seems reasonable to consider a more aggressive treatment in younger individuals. ${ }^{11}$

The valuation of the data "positive margins" in the examination should be performed with caution, due to the great variability of concepts in the definition of the margins. ${ }^{11}$ Abide et al. conducted a study interviewing 11 pathologists on the definition of positive margins, resulting in great disparity of responses even within the same hospital. The definition of "coincidental" consisted of the presence of a tumor between zero and $5 \mathrm{~mm}$ from the surgical margin. Likewise, 25 surgeons were questioned about their conduct before the histopathological examination, with a tendency to surgical reintervention, if the margins were positive, and to observation, if the margins were coincidental. ${ }^{15}$ Thus, there is still no consensus among dermatopathologists about the concept of positive margins in histopathological examination. ${ }^{11}$

In addition, the presence of compromised histologic margins does not necessarily predict recurrence., ${ }^{9}$ Immediate reintervention with subsequent histopathological analysis was able to evidence residual tumor in a mean of only $33 \%$ of cases (7-45\%). The reasons for this finding are: the tumor was present only in the surgical margin, not surpassing it; the histopathological analysis by the traditional method was not able to detect the tumor, since only $0.2 \%$ to $2 \%$ of the material is analyzed with the cuts in the usual technique; or the tumor cells were destroyed by postoperative inflammation. $^{11}$

Evidence shows that basal cell carcinomas disappear after biopsy in $25 \%$ to $34 \%$ of patients, with a primary role of the immune system in tumor destruction. ${ }^{5,11}$ Studies suggest an important role of CD4+ T lymphocytes and their inflammatory cytokines in the spontaneous regression of epithelial carcinomas. ${ }^{5}$

Similarly, tumors whose resection margins were negative may also recur due to the persistence of a multifocal tumor or to a small sample evaluated by the dermatopathologist, unless Mohs surgery was performed. ${ }^{9,12}$

The choice of the best treatment should be individualized, considering factors that may influence the prognosis of basal cell carcinoma, such as tumor size, location, histological type, definition of compromised margin and clinical conditions of the patient. ${ }^{9}$ In addition, the follow-up of the patient with diagnosis of basal cell carcinoma should be performed periodically, independently of the therapeutic approach adopted, since a 3-year follow-up will identify $66 \%$ of relapses and $75 \%$ of recurrences will occur in 5 years. ${ }^{6,9}$

Basal cell carcinomas are commonly classified as aggressive and non-aggressive. Micronodular, infiltrative, and sclerodermiform histologic subtypes are considered aggressive in contrast to the superficial and nodular subtypes. ${ }^{4}$ A study conducted by Boulinguez et al. showed a change in the histological pattern of recurrences in $24 \%$ of the carcinomas studied (8 of 33), evolving to a more aggressive subtype. ${ }^{16}$

Regarding tumor site, the great majority of BCCs, whose margins are positive, are located in the head and neck, and the medial portion of the face and the nose are the sites with the highest incidence. ${ }^{3,12}$ A meta-analysis published on this subject found a relative risk 2.24 higher of basal cell carcinomas in the nose and ears than in the rest of the body. ${ }^{17}$ Many authors agree that the perinasal and periocular areas consist of sites of worse prognosis, with a higher frequency of relapses in these regions in incompletely excised

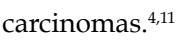

The lateral margin is more commonly involved than the deep margin, but it is consensual that the recurrence increases when the deep margin is compromised.,11

In addition, basal cell carcinomas show an increased risk of recurrence in lesions larger than $2 \mathrm{~cm} .{ }^{6}$ The influence of all the aforementioned factors on the recurrence of basal cell carcinoma remains contradictory between the different studies. ${ }^{6,79,11,12,13}$

Most authors recommend a less invasive approach in less aggressive tumors, that is, primary, small tumors, which do not occur in the center of the face and ears, with superficial or nodular histology and with lateral margins involvement, in elderly patients with low life expectancy. ${ }^{4,6,11}$

\section{MATERIALS AND METHODS}

This is an observational and retrospective study with an intentional probabilistic sample with sequential selection, performed with the approval of the Research Ethics Committee (REC) of the Federal University of Paraná (UFPR), through the analysis of records of all cases of basal cell carcinoma diagnosed in the period between January 2003 and December 2009 at the Hospital de Clínicas of the Federal University of Paraná (HC-UFPR). The verification of data was conducted from the Hospital Registry of Cancer of the hospital. More recent cases have not been reviewed in order to achieve a minimum follow-up period of 5 years for all patients from the treatment, a period recommended by the literature.

Subsequently, the histopathological reports of these carcinomas were reviewed through the database of the Pathology Department of the Hospital de Clínicas of the Federal University of Paraná (HC-UFPR), including all patients submitted to surgical excision of histologically confirmed basal cell carcinoma and presenting positive margins in the present anatomopathological examination. The definition of "positive margins" considered was the description of compromised margins, coincidental or exiguous, in the examination. All tumors were treated with curative intent by excision with simple primary closure or skin grafts and flaps. 
Patients whose lesion had less than 5 years of follow-up, with syndromes predisposing to the appearance of basal cell carcinomas, submitted to punch or incisional biopsies with diagnostic intent or treated with non-surgical methods were excluded from the study.

Following the determination of this subgroup of patients with basal cell carcinoma demonstrating positive margins after surgical excision, data were collected from a review of medical records related to recommended medical practice: clinical observation or surgical reintervention. Clinical characteristics such as sex and age of the patients, site and size of the tumor, presence or absence of ulceration, histological type and type of compromised margin were collected to evaluate these variables as determinants of greater recurrence of the neoplasia. Data not described in the medical record were acquired through telephone contact with patients or relatives.

Statistical analysis was performed using the non-parametric Mann-Whitney test (variable "age") and Fisher's exact test (other variables). The recurrence time between the groups was evaluated with the Student $t$ test (variable "months" in relation to the groups), being a $p>0.05$ considered statistically significant.

\section{RESULTS}

In the period between January 2003 and December 2009, 487 patients had 507 diagnoses of histologically confirmed basal cell carcinoma in the Hospital de Clínicas of the Federal University of Paraná (HC-UFPR). Of the total, 353 tumors were surgically excised, and free margins were found in the histopathological report, while 57 were treated with other non-surgical methods (curettage and electrocoagulation, cryotherapy, imiquimod, radiotherapy). Twelve tumors presented spontaneous resolution after biopsy, while 36 tumors were not treated in the hospital due to loss of follow-up.

In 49 patients who underwent surgical excision of carcinomas, there was evidence of a compromised margin in the histopathology, accounting for $12.18 \%$ of the total.

However, due to follow-up of less than five years, 8 patients were excluded from the project. Of the 41 patients evaluated, 35 were observed periodically, and 5 cases of relapse (15\%) occurred. In 6 cases submitted to an early surgical reintervention, there were 3 cases $(50 \%)$ of relapse. The mean recurrence time in the 'observation' group was 25 months and in the 'reintervention' group was 7 months ( $p=0.0005509$ ), and the standard deviation (SD) for the first group was 4.36 and for the second group, 1.73 (Graph 1). In both groups, mean recurrence time was 18.5 months.

The mean age of patients was 66.42 years (35-87 years). There was no significant difference between the sexes $-51.22 \%$ men and $48.78 \%$ women, with no statistically significant difference between groups ("observation" versus "reintervation") regarding age $(p=0.91)$ and sex $(p=1.0)$ (Tables 1 and 2$)$.

The main anatomical site of incompletely excised basal cell carcinoma found in the study was head and neck, with 37 cases occurring in these regions and only 4 in the rest of the body, with $39.02 \%$ occurring in the nasal region (Table 3). Most lesions (82.93\%) comprised tumors smaller than 2 centimeters in diameter (Table 4). The predominant histological type was nodular basal cell carcinoma $(85.36 \%)$ (Table 5).

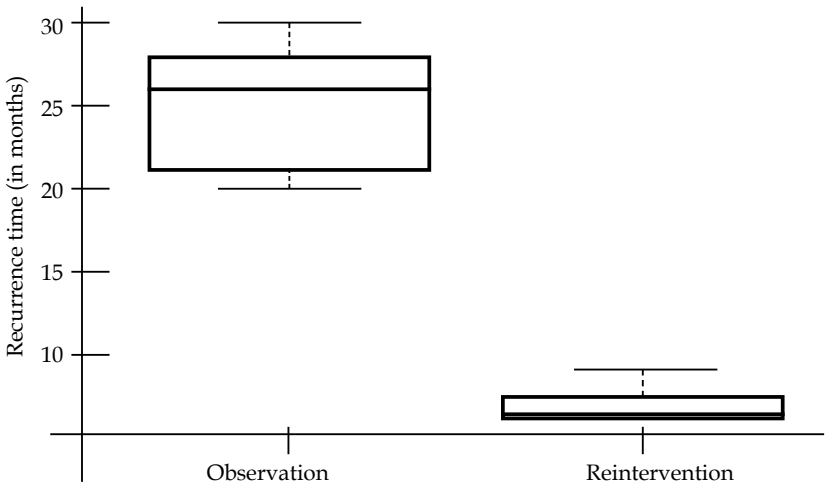

GRAPH 1: Time of recurrence in the groups 'observation' and 'reintervention'

TABLE 1: Age

\begin{tabular}{llllll}
\hline & Mean & N & SD & Minimum & Maximum \\
\hline Observation & 65.51 & 35 & 13.68 & 35 & 85 \\
Reintervation & 67.33 & 6 & 14.78 & 45 & 87 \\
Total & 66.42 & 41 & 14.23 & 35 & 87 \\
\hline
\end{tabular}

Mann-Whitney test $(\mathrm{p}=0.9118)$

TAble 2: Sex

\begin{tabular}{lllllll}
\hline & \multicolumn{2}{c}{ Observation } & \multicolumn{2}{c}{ Reintervation } & \multicolumn{2}{c}{ Total } \\
\hline SEX & $\mathbf{N}$ & $\mathbf{0}$ & $\mathbf{N}$ & $\mathbf{0}$ & $\mathbf{N}$ & $\mathbf{0}$ \\
\hline Men & 18 & $51.40 \%$ & 3 & $50 \%$ & 21 & $51.22 \%$ \\
Women & 17 & $48.60 \%$ & 3 & $50 \%$ & 20 & $48.78 \%$ \\
Total & 35 & $100.00 \%$ & 6 & $100 \%$ & 41 & $100.00 \%$
\end{tabular}

Fisher's exact test $(\mathrm{p}=1.0)$

TABLE 3: Tumor site

\begin{tabular}{lllllll}
\hline & \multicolumn{2}{l}{ Observation } & \multicolumn{2}{l}{ Reintervation } & \multicolumn{2}{l}{ Total } \\
\hline Tumor Site & $\mathbf{N}$ & $\mathbf{0}$ & $\mathbf{N}$ & $\mathbf{0}$ & $\mathbf{N}$ & $\mathbf{\%}$ \\
\hline Nasal & 14 & $40.00 \%$ & 2 & $33.34 \%$ & 16 & $39.02 \%$ \\
Periocular & 3 & $8.58 \%$ & 0 & $0.00 \%$ & 3 & $7.32 \%$ \\
Ear & 2 & $5.72 \%$ & 0 & $0.00 \%$ & 2 & $4.88 \%$ \\
$\begin{array}{l}\text { Perioral } \\
\text { Rest of the }\end{array}$ & 1 & $2.86 \%$ & 1 & $16.67 \%$ & 2 & $4.88 \%$ \\
$\quad 12$ & $34.29 \%$ & 2 & $33.34 \%$ & 14 & $34.14 \%$ \\
$\quad$ face & & & & & & \\
$\quad \begin{array}{l}\text { Rest Of The } \\
\quad 3\end{array}$ & $3.58 \%$ & 1 & $16.67 \%$ & 4 & $9.76 \%$ \\
$\quad$ Body & 35 & $100.00 \%$ & 6 & $100.00 \%$ & 41 & $100.00 \%$
\end{tabular}

Fisher's exact test $(\mathrm{p}=0.6257)$

TABle 4: Tumor size

\begin{tabular}{lllllll}
\hline & \multicolumn{2}{l}{ Observation } & \multicolumn{2}{l}{ Reintervation } & \multicolumn{2}{l}{ Total } \\
\hline Tumor Size & $\mathbf{N}$ & $\mathbf{0}$ & $\mathbf{N}$ & $\mathbf{0}$ & $\mathbf{N}$ & $\%$ \\
\hline$<1 \mathrm{~cm}$ & 17 & $48.58 \%$ & 4 & $66.66 \%$ & 21 & $51.22 \%$ \\
$1-2 \mathrm{~cm}$ & 12 & $34.28 \%$ & 1 & $16.67 \%$ & 13 & $31.71 \%$ \\
$>2 \mathrm{~cm}$ & 6 & $17.14 \%$ & 1 & $16.67 \%$ & 7 & $17.07 \%$ \\
Total & 35 & $100.00 \%$ & 6 & $100.00 \%$ & 41 & $100.00 \%$ \\
\hline
\end{tabular}

Fisher's exact test $(\mathrm{p}=0.8385)$ 
The clinical variables - tumor size, site, histological type, presence of ulceration and type of compromised margin - did not differ significantly between the 'observation' versus 'reintervention' groups, and it was not possible, in this study, to consider them as determining factors in the variability of relapse rates (Tables 3 to 7 ).

\section{DISCUSSION}

The rate of positive margins after surgical excision of basal cell carcinoma presented in this study was $12.18 \%$ (49 of 402 tumors treated surgically), a very favorable result when compared with the literature. ${ }^{6,7,9,10,13-15}$ The low rate of incompletely excised tumors probably reflects the correct surgical indication and adequate professional qualification of the physicians of the Hospital de Clínicas of the Federal University of Paraná (HC-UFPR).

Compared with the small number of patients in the sample, only 8 cases of relapse were observed in the two groups (5 in the 'observation' group and 3 in the 'surgical reintervention' group). In addition to demonstrating the less aggressive nature of the lesions treated, this data points to the difficulty of performing a retrospective study in a single center, given the rarity of basal cell carcinomas with positive margins. Multicentric studies would be the best research option to clarify doubts regarding the management of these patients. ${ }^{4}$

The mean recurrence time in most studies is less than 3 years for basal cell carcinoma, consistent with the 18.5 months found in this study. ${ }^{12}$

The mean age of the patients (66.42 years) was compatible with the findings in other studies. There was no age difference between

TABLE 5: Histological type

\begin{tabular}{lllllll}
\hline & \multicolumn{2}{l}{ Observation } & \multicolumn{2}{l}{ Reintervation } & \multicolumn{2}{l}{ Total } \\
\hline Histological Type & $\mathbf{N}$ & $\mathbf{0}$ & $\mathbf{N}$ & $\mathbf{0}$ & $\mathbf{N}$ & $\%$ \\
\hline Solid / Nodular & 30 & $85.71 \%$ & 5 & $83.33 \%$ & 35 & $85.36 \%$ \\
Micronodular & 2 & $5.72 \%$ & 0 & $0.00 \%$ & 2 & $4.88 \%$ \\
Sclerodermiform & 3 & $8.57 \%$ & 1 & $16.66 \%$ & 4 & $9.76 \%$ \\
Total & 35 & $100.00 \%$ & 6 & $100 \%$ & 41 & $100.00 \%$ \\
\hline Fisher's exact test (p=0.7009) & & & & &
\end{tabular}

TABLE 6: Ulceration

\begin{tabular}{lllllll}
\hline & \multicolumn{2}{l}{ Observation } & \multicolumn{2}{l}{ Reintervation } & \multicolumn{2}{l}{ Total } \\
\hline $\begin{array}{l}\text { Presence of } \\
\text { ulceration }\end{array}$ & $\mathbf{N}$ & $\%$ & $\mathbf{N}$ & $\%$ & $\mathbf{N}$ & $\%$ \\
\hline Yes & 18 & $51.43 \%$ & 2 & $33.33 \%$ & 20 & $48.78 \%$ \\
No & 17 & $48.57 \%$ & 4 & $66.67 \%$ & 21 & $51.22 \%$ \\
Total & 35 & $100.00 \%$ & 6 & $100.00 \%$ & 41 & $100.00 \%$ \\
\hline
\end{tabular}

Fisher's exact test $(\mathrm{p}=0.6628)$

TABLE 7: Compromised margins

\begin{tabular}{lllllll}
\hline & \multicolumn{3}{l}{ Observations } & \multicolumn{5}{l}{ Reintervention } & Total \\
\hline $\begin{array}{l}\text { Compromised } \\
\text { margins }\end{array}$ & $\mathbf{N}$ & $\mathbf{0}$ & $\mathbf{N}$ & $\%$ & $\mathbf{N}$ & $\%$ \\
\hline Lateral & 11 & $31.42 \%$ & 2 & $33.33 \%$ & 13 & $31.70 \%$ \\
Deep & 19 & $54.28 \%$ & 2 & $33.33 \%$ & 21 & $51.22 \%$ \\
Both & 5 & $14.30 \%$ & 2 & $33.33 \%$ & 7 & $17.08 \%$ \\
Total & 35 & $100.00 \%$ & 6 & $100.00 \%$ & 41 & $100.00 \%$ \\
\hline
\end{tabular}

Fisher's exact test $(\mathrm{p}=0.7362)$ the 'observation' and 'surgical reintervention' groups, in contrast to the findings of Kumar et al., who found a higher mean age in the group of patients who underwent a new surgery. ${ }^{3}$ There was also no difference between sexes. Corroborating the results of this study, most of the series did not demonstrate significant variables of age and sex. ${ }^{3}$

Most $(90.24 \%)$ of lesions of basal cell carcinoma with positive margins were located in the head region, with $39.02 \%$ in the nasal region. Nose, chin, medial corner of the eye, lower eyelid and nasogenian sulcus present a risk of compromised margins greater than $10 \%$ and recurrence of the disease around $30 \%{ }^{7}$ The reason for the largest number of carcinomas incompletely excised in these regions lies in the reluctance to remove skin in the proper amount due to the impairment of the cosmetic units and the fusion of embryonic clefts at these sites. ${ }^{3}$

Most of lesions were smaller than $2 \mathrm{~cm}$, denoting patients' demand for medical services and the correct and early diagnosis of physicians, as seen in other studies., 3,9,10

The predominant histological type of basal cell carcinoma in the study was nodular (85.36\%). Nodular BCC is the most common clinical variant, accounting for approximately $60 \%$ of all primary basal cell carcinomas. ${ }^{1}$ Like the study by Wilson et al. ${ }^{7}$, it was not possible to demonstrate a statistically significant difference between the two groups in relation to the histological type, although the majority of the authors emphasize that tumors with more aggressive histological subtype (infiltrative and sclerodermiform) are associated with higher recurrence rates. ${ }^{3,6,11}$

Although there was no statistical significance between the two groups due to the small sampling, the deep margin was more frequently compromised ( $51.22 \%$ of the cases), in contrast to the literature where the margin most affected is the lateral margin. 3,11,12

We lack well-designed studies to evaluate the importance of the presence of ulceration in the relapse of incompletely excised basal cell carcinomas.

Facing the difficulty of a larger sample of basal cell carcinomas with positive margins in this retrospective study, it was observed that the ideal would be to conduct a prospective study with a minimum duration of 5 years, evaluating three main subgroups: patients with resected tumors and free margins, patients with positive margins and surgical reintervention, and patients with positive margins and periodically followed up. Thus, the evaluation of the clinical variables responsible for the higher rate of relapse would be more reliably performed.

\section{CONCLUSION}

In this study, we concluded that the percentage of basal cell carcinomas incompletely excised in the Hospital de Clínicas of the Federal University of Paraná (HC-UFPR) is quite reasonable $(12.18 \%)$, and is consistent with the literature findings. It was not possible to consider the clinical variables studied as determining factors in the variability of recurrence rates.

The individualized evaluation of each patient in the choice of the best management against basal cell carcinoma with positive margins is the way to further decrease the recurrence rates of these tumors, reserving the surgical reintervention for the most aggressive cases.] 


\section{REFERENCES}

1. Bolognia JL, Jorizzo JL, Rapini RP. Dermatology 2nd ed. St Louis: Mosby; 2008 p. 1641-58.

2. Sampaio SAP, Rivitti EA. Dermatologia 3. ed. São Paulo: Artes Médicas; 2008; p. 1163-66.

3. Kumar P, Orton $\mathrm{Cl}$, McWilliam LJ, Watson S. Incidence of incomplete excision in surgically treated basal cell carcinoma: a retrospective clinical audit. $\mathrm{Br} \mathrm{J}$ Plast Surg. 2000;53:563-6.

4. Boulinguez S, Grison-Tabone C, Lamant L, Valmary S, Viraben R, Bonnetblanc $\mathrm{JM}$, et al. Histological evolution of recurrent basal cell carcinoma and therapeutic implications for incompletely excised lesions. Br J Dermatol. 2004;151:623-6.

5. Rieger KE, Linos E, Egbert BM, Swetter SM. Recurrence rates associated with incompletely excised low-risk nonmelanoma skin cancer. J Cutan Pathol. 2010;37:59-67

6. Berlin J, Katz KH, Helm KF, Maloney ME. The significance of tumor persistence after incomplete excision of basal cell carcinoma. J Am Acad Dermatol. 2002;46:549-53.

7. Wilson AW, Howsam G, Santhanam V, Macpherson D, Grant J, Pratt CA, et al. Surgical management of incompletely excised basal cell carcinomas of the head and neck. Br J Oral Maxillofac Surg. 2004;42:311-4.

8. Rowe DE, Carroll RJ, Day CL Jr. Long term recurrence rates in previously untreated (primary) basal cell carcinoma: implications for patient follow up. J Dermatol Surg Oncol. 1989;15:315-28.

9. Nagore E, Grau C, Molinero J, Fortea JM. Positive margins in basal cells carcinoma: relationship to clinical features and recurrence risk: A retrospective study of 248 patients. J Eur Acad Dermatol Venereol. 2003;17:167-70.

10. Kimyai-Asadi A, Alam M, Goldberg LH, Peterson SR, Silapunt S, Jih MH. Efficacy of narrow-margin excision of well-demarcated primary facial basal cell carcinomas. J Am Acad Dermatol. 2005;53:464-8.

11. Rios-Buceta L. Management of Basal cell carcinomas with positive margins Actas Dermosifiliogr. 2007;98:679-87.

12. Hallock GG, Lutz DA. A prospective study of the accuracy of the surgeon's diagnosis and significance of positive margins in nonmelanoma skin cancers. Plast Reconstr Surg. 2001;107:942-7.

13. Liu FF, Maki E, Warde P, Payne D, Fitzpatrick P. A management approach to incompletely excised basal cell carcinomas of skin. Int J Radiat Oncol Biol Phys. 1991;20:423-8

14. Sussman LA, Liggins DF. Incompletely excised basal cell carcinoma: a management dilemma. Aust N Z J Surg. 1996;66:276-8.

15. Abide JM, Nahai F, Bennett RG. The meaning of surgical margins. Plast Reconstr Surg. 1984;73:492-7.

16. Friedman HI, Williams T, Zamora S, al-Assaad ZA. Recurrent basal cell carcinoma in margin-positive tumors. Ann Plast Surg. 1997;38:232-5.

17. Rogalski C, Kauer F, Simon JC, Paasch U. Meta-analysis of published data on incompletely excised basal cell carcinomas of the ear and nose with introduction of an innovative treatment strategy. J Dtsch Dermatol Ges. 2007;5:118-26.
MAILING ADDRESS:

Luiz Eduardo Fabricio de Melo Garbers

R. General Carneiro, 181

Centro

80060-150 Curitiba, PR

Brazil

Email:legarbers@gmail.com

How to cite this article: Lara F, Santamaria JR, Garbers LEFM. Recurrence rate of basal cell carcinoma with positive histopathological margins and related risk factors. An Bras Dermatol. 2017;92(1):58-62. 